\title{
A feasibility study on exploitation of atmospheric water resources using cloud seeding in arid and semi arid parts of Iran
}

\begin{abstract}
Water resource management and optimum use of all available water resources are ways for the adaptation of climate change and drought conditions. Weather modification, commonly known as cloud seeding, is the application of scientific technology that can enhance a cloud's ability to produce precipitation. Cloud seeding projects have being performed in Iran since 1999, as one of the most important strategies to increase water supplies. However, determining the time and place of cloud seeding operation are the basic necessities to achieve the best possible results. This paper explains innovative and scientific methods of feasibility study of Tehran province (semi-arid area) and Hormozgan province (arid area) by meteorological stations data, upper air data, satellite imagery (TRMM), weather radars products, topographic and vegetation maps. Factor analysis and World Meteorological Organization classification methods of PEP were applied to determine proper seeding time. Eventually, cloud seeding susceptible areas were classified as levels and altitudes. In Tehran province, the results showed that the northwest, west and central catchments are capable for cloud seeding operation in December, January, February and March at an altitude of 25003000 meters. Suitable months of cloud seeding operation in the north and northwest of the catchment of Hormozgan province were January, February and March, in order of priority.
\end{abstract}

Volume 5 Issue 2 - 2021

\author{
Samaneh Poormohammadi,' Mohammad \\ Hassan Rahimian, ${ }^{2}$ Mehran Fatemi ${ }^{3}$ \\ 'PhD in watershed science and engineering and research expert \\ of National Cloud Seeding Research Center, water research \\ institiute, Iran \\ ${ }^{2}$ Facualty member of National Salinity Research Center, Iran \\ ${ }^{3}$ Facualty member of Meybod University, Iran
}

\author{
Correspondence: Samaneh Poormohammadi, PhD in \\ watershed science and engineering and research expert of \\ National Cloud Seeding Research Center, water research \\ institiute, Yazd, Iran, Tel +9835 I825055 I-2, Fax +9835I 0825 I 403, \\ Email s.poormohammadi@gmail.com
}

Received: March 20, 2019 | Published: April |4, 202 I

\section{Introduction}

Weather modification activities to enhance water supplies have been conducted for a wide variety of users including water resource managers, hydro-electric power companies and agricultural sectors (AMS, 1992). Cloud seeding, a form of weather modification, is the attempt to change the amount or type of precipitation that falls from clouds, by dispersing substances into the air that serve as cloud condensation or ice nuclei, which alter the microphysical processes within the cloud. The usual intent is to increase precipitation (rain or snow), but hail and fog suppression are also widely practiced in airports. Cloud seeding is no longer considered as a fringe science, while it is considered as a mainstream tool to improve precipitation of rain and snow. Advances on this technology, espicially during the recent years, has produced reliable results that turn cloud seeding technique into a dependable water-supply practice for many regions. ${ }^{6}$ While this technique has been practiced widely around the world, its effectiveness is still a matter of academic debates. In 2004 the United States National Research Council released a report stating that to date, there is still no convincing scientific proof of the efficacy of intentional weather modification, as it only has $30 \%$ or less chance of success. ${ }^{1-7}$ Against existing constraints and debates, some merits exist for this technique that forces governments to support and use this technique in their national water harvesting plans and strategies, espicilally in water scarce arid/semi arid regions of the worlds.

Iran, known as an arid/semi arid country, is now faced with qualitative and quantitative deterioration of its water resources, which has been accelerated during the last decade. Periodic long term occurances of droughts due to global climate change and mismangement of existing water rsources are the major reasons for these threats. Under such a condition, proper water resource management strategies and optimum use of all available water resources are key solustions to adapt with prevailing climate change and drought hazards. Iranian cloud seeding projects have being started from 1999, as one of the national strategies to increase water supplies at differetn parts of the country. However, determining the apropriate time and place of cloud seeding operation are the basic necessities to achieve the best possible results. This always investigates in form of a feasibility study. A few Iranian literatures exist in this field, e.g. Poormohammadi et al. ${ }^{48}$ while further researches seem necessary on this important issue. The aim of this study is to determine the areas prone to cloud seeding in the two catchments of Tehran and Hormozgan. For this purpose, two cloud seeding projects of Tehran and Hormozgan provinces were assessed, in detail.

\section{Methodology}

This research was conducted at Tehran and Hormozgan provinces of Iran (Figure 1). Tehran is located in semi-arid area and its annual precipitation is about $250 \mathrm{~mm}$. Hormozgan is located in arid area and its annual precipitation is about $170 \mathrm{~mm}$. A feasibility study on cloud seeding, needs most of synoptic meteorological data of all stations in and around of the study area. These data include maximum (max), minimum ( $\mathrm{min}$ ) and mean relative humidity, wind speed, dominant wind direction, rainfall, frost and fog days. In the next step, suitable time of cloud seeding will be selected using mentioned parameter and up-atmospheric data. In the final step, suitable sites will be specified using spatial parameters, consisting data of Radar and weather stations, iso-rain map, cloudiness map and topography map, as well. Figure 2 shows the research flowchart, in brief. In this research, suitable areas for cloud seeding performance were determined with the help of PEP (Precipitation Enhancement Project) method. This method was approved in $7^{\text {th }}$ WMO Congress in Weather Modification Program in 1976. The most important stages of this program are as follow:

Stage 1: questionnaires and preselection,

Stage 2: site visits and climatological studies,

Stage 3: detailed microphysical investigations and other studies. 


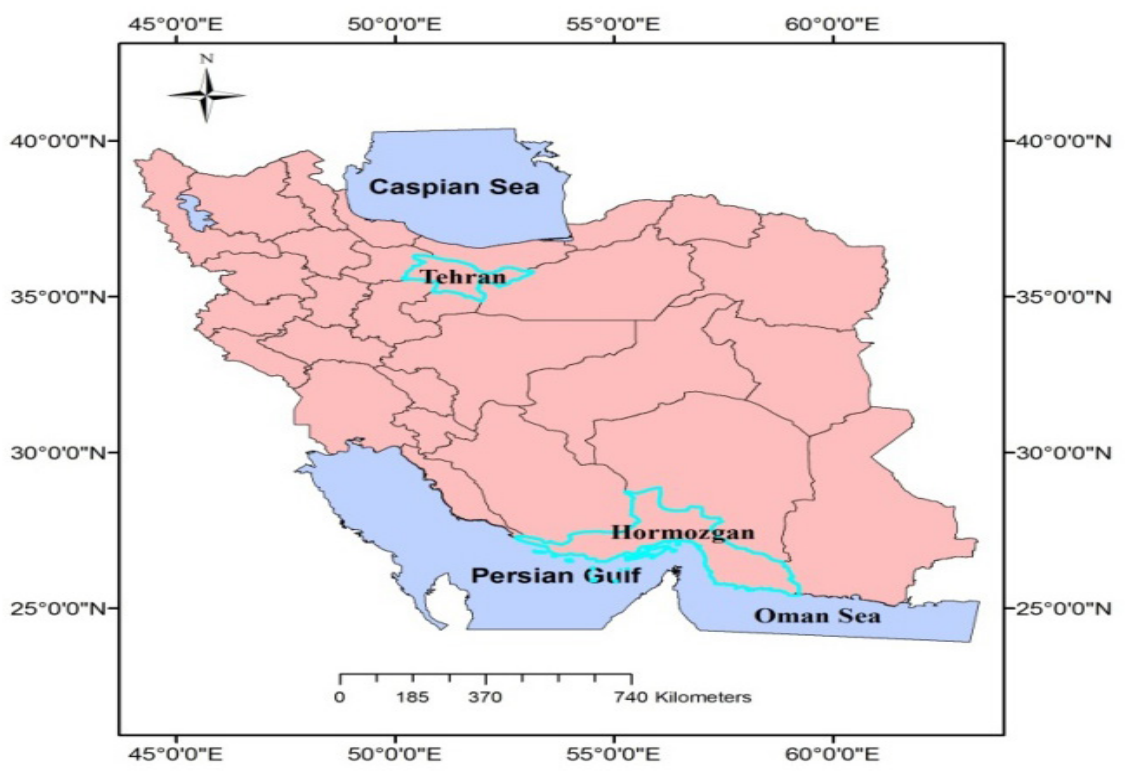

Figure I Tehran and Hormozgan provinces on the country map of Iran.

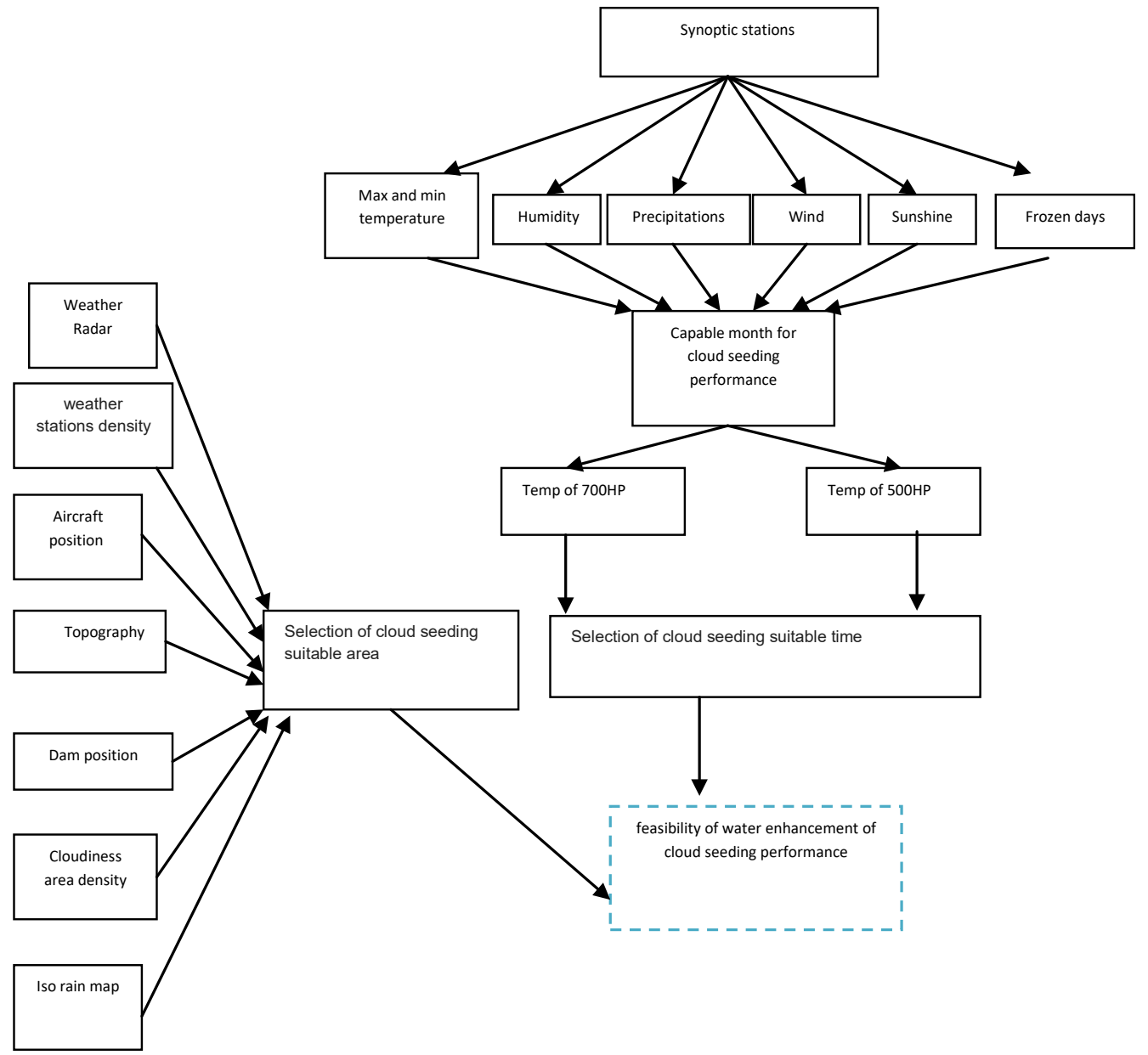

Figure 2 Feasibility study steps for cloud seeding performance.

In the first stage, PEP site-selection criteria should be defined. Table 1 is an objective method of allotting marks to site under various criteria. It includes physical characteristics of site, such as size, degree of homogeneity, characteristics of precipitation (including annual amount and regime, liquid to solid at ground, length of rainy season), availability of meteorological data (including density of rain gauge network, length of record), other data (radar, rawinsound) and facilities has been gathered in the stage. 
Table I PEP site selection criteria objective method of allotting marks to site under various criteria

\begin{tabular}{|c|c|c|c|c|c|c|}
\hline \multicolumn{3}{|l|}{ Criterion } & \multicolumn{4}{|l|}{ Score } \\
\hline $\mathbf{0}$ & & I & 2 & 3 & 4 & 5 \\
\hline I. Size of site $(\mathrm{km} 2 \times 103)$ & $<20$ & $20-25$ & $25-30$ & $30-40$ & $40-50$ & $\geq 50$ \\
\hline 2. Degree of homogeneity & $f+u+h+m$ & M & $h+m$, & $\mathrm{u}+\mathrm{h}$ & $\mathrm{H}$ & $f, u$ \\
\hline f-flat, u-undulating, h-hilly, & $f+u+m$ & $f+u+h$ & $f+h$ & & & $f+u$ \\
\hline \multirow[t]{2}{*}{ m-mountainous } & $f+m$ & $\mathrm{u}+\mathrm{m}$ & $\mathrm{m}$ & & & \\
\hline & $f+h+m$ & $\mathrm{u}+\mathrm{h}+\mathrm{m}$ & & & & \\
\hline 3.Annual pptn. & $\leq 25$ & $25-30$ & $31-35$ & $35-40$ & $4 \mid-50$ & $51-70$ \\
\hline$(\mathrm{cm})$ & $\geq 100$ & & $91-99$ & $86-90$ & $81-85$ & $71-80$ \\
\hline 4. Pptn. Regime & a (warm) & $\mathrm{D}$ & $\mathrm{a}($ cold $)$ & b(cold) & $c+b+a$ & c \\
\hline a-arog., b-conv., & b (warm) & & & $a+b$ & & $c+a$ \\
\hline c-extra-trop. fronts & & & & $e, f$ & & \\
\hline \multicolumn{7}{|l|}{ d-trop. cyclone, } \\
\hline \multicolumn{7}{|l|}{ e-monsoon, f-equat. } \\
\hline 5. Portion of pptn. as liquid (\%) & $<60$ & $60-70$ & $70-80$ & $80-85$ & $85-90$ & $>90$ \\
\hline 6. Length of rainy season & $>8$ & $8-7$ & $7-6$ & $6-5$ & $5-4$ & $4-3$ \\
\hline \multicolumn{7}{|l|}{ (months) } \\
\hline 7. Density of gauge (per 1000 km2) & $<.1$ & $0.1-0.5$ & $0.5-2$ & $2-4$ & $4-6$ & $>6$ \\
\hline 8. Length of record (years) & $<10$ & Oct-15 & $15-20$ & $20-30$ & $30-40$ & $>40$ \\
\hline 9. Other data: & $b, c$ & $a<5$ & $5<a<10$ & $a>10$ & $(a>10)+b$ & \\
\hline a-rawinsonde data, & & & $(a<5)+b$ & $(5<a<10)+b$ & $(a>10)+c$ & \\
\hline b-aircraft data, & & & $(a<5)+c$ & $(5<a<10)+c$ & & \\
\hline \multicolumn{7}{|l|}{ c-radar data } \\
\hline 10. Flight restrictions: & $\mathrm{d}$ & $b+x$ & $b+y$ & $a+x$ & $A+y$ & $a+z$ \\
\hline a-none, b-minor, c-severe, & $c+x$ & $c+y$ & $c+z$ & $b+z$ & & \\
\hline \multicolumn{7}{|l|}{ d-ban } \\
\hline \multicolumn{7}{|l|}{ Facilities: } \\
\hline \multicolumn{7}{|l|}{$x$-poor, $y$-average, z-modern } \\
\hline II. Communications: & C & $\mathrm{B}$ & $c+d+e$ & $a+d$ & $a+d+e$ & \\
\hline a-good road system, & & $c+d$ & $b+d$ & $a+e$ & & \\
\hline b-satisfactory roads, & & $c+e$ & $b+e+a$ & $b+d+e$ & & \\
\hline \multicolumn{7}{|l|}{ c-bad roads, d-postal service, } \\
\hline \multicolumn{7}{|l|}{ e-telephones } \\
\hline 12. Working conditions: & $\mathrm{b}$ & $b+c$ & $a+c$ & $a+c+d$ & $a+c+$ & \\
\hline a-satisfactory accommodation & & $b+c$ & $a+d$ & $a+d+e$ & & \\
\hline b-poor accommodation & & $b+c$ & $a+e$ & $a+c+e$ & & \\
\hline c-medical facilities & & & $b+c+d$ & $b+c+d+e$ & & \\
\hline d-cultural facilities & & & $b+c+$ & e, & & \\
\hline e-adequate electric power & & & & $b+d+e$ & & \\
\hline
\end{tabular}

Citation: Poormohammadi S.A feasibility study on exploitation of atmospheric water resources using cloud seeding in arid and semi arid parts of Iran. Int J Hydro. 202I;5(2):66-70. DOI: I0.15406/ijh.202 I.05.00267 


\section{Result and discussion}

\section{Tehran}

Table 2 shows capable months of cloud seeding performance in Tehran province. Jan, Feb, Marc, Apr and Dec are suitable times for cloud seeding performance. Maximum precipitation would be happened in Mar., Jan. has minimum temperature, while Apr. has maximum temperature. based on PEP approach, potential watersheds of Tehran province for cloud seeding are shown in Table 3. This table shows that Taleqan-Alamut, Eshtehard, Qazvin and Hashtgerd were selected for cloud seeding performance. With specialist's idea can be omitted watershed that have score of less than 62 . Other watershed that have high score, were not selected because they were not in the operating range.

Table 2 Capable time of cloud seeding performance in Tehran province

\begin{tabular}{llll}
\hline Max temperature & min temperature & Mean precipitation & month \\
\hline 13.7 & -6 & 34 & Jan. \\
17.2 & -4.9 & 33 & Feb. \\
22.8 & -1.9 & 38 & Mar. \\
28.7 & 3.6 & 31 & Apr. \\
15.9 & -3.5 & 33 & Dec. \\
\hline
\end{tabular}

Table 3 The final prominenceof watershedbasis onthe World Meteorological Organization

\begin{tabular}{llll}
\hline Score & Basin & Score & Basin \\
\hline 60 & Namak lake & 75 & Qaemshahr \\
59 & Ramsar-Chaluse & 70 & Taleqan-Alamut \\
59 & Semnan & 69 & Tehran-Karaj \\
59 & Kavir semnan & 68 & Babol-Amol \\
59 & nobaran & 67 & Lavasanat \\
59 & Noshahr-Nur & 66 & Hashtgerd \\
57 & Ivanaki & 64 & Sharifabad \\
57 & khomajin & 64 & Qazvin \\
57 & Firuzkuh & 64 & Varamin \\
56 & 4save & 63 & Eshtehard \\
55 & Save & 63 & Sari-Neka \\
55 & Humand-Absard & 62 & damavand \\
53 & Zarand Save & 62 & Garmsar \\
52 & Mobarake & 61 & Sorkhe \\
- & - & 61 & masile \\
\hline
\end{tabular}

\section{Hormozgan}

Table 4 shows capable month of cloud seeding performance in Hormozgan province. Jan., Feb., Mar., Dec. and Apr. were found suitable for cloud seeding performance. Maximum precipitation would be happened in Jan; also Jan. has minimum temperature and Apr. has maximum temperature. Figure 3 shows suitable site of cloud seeding performance in Hormozgan province, which has been created using the PEP method. Considering this figure, elevated areas of central and south west of Hormozgan province are potential sites for cloud seeding performance. The results of this article are consistent with the articles of Javanmard 2001, Pourmohammadi 2010, Pourmohammadi et al. ${ }^{2}$
Table 4 Capble time of cloud seeding performance in Hormozgan province

\begin{tabular}{lllll}
\hline $\begin{array}{l}\text { Max } \\
\text { temperature }\end{array}$ & $\begin{array}{l}\text { Min } \\
\text { temperature }\end{array}$ & $\begin{array}{l}\text { Mean } \\
\text { precipitation }\end{array}$ & month & Preference \\
\hline 26.7 & 7.1 & 48 & Jan. & I \\
28.2 & 8.8 & 39 & Feb. & 2 \\
21.2 & 12.9 & 35 & Mar. & 3 \\
29 & 8 & 27.3 & Dec. & 4 \\
37.1 & 17.2 & 8.2 & Apr. & 5 \\
\hline
\end{tabular}

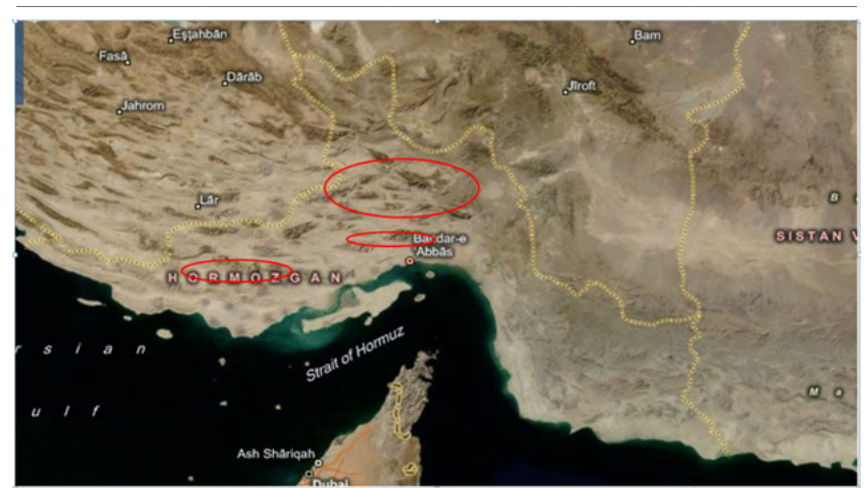

Figure 3 Suitable areas for cloud seeding in Hormozgan province (red circles).

\section{Conclusion}

This research show that cloud seeding technique can be a useful tool for harvesting of atmospheric water, weather modification and supply of water for agricultural sector and watershed management. Taleghan-Alamut, Hashtgerd, Qazvin, Tehran-Karaj Eshtehard and Manjil are suitable sites to cloud seeding performance in Jan, Feb, Marc, Apr and Dec in Tehran province, at an average altitude of 2,500 to 3,000 meters. It was also carried out at Hormozgan province where have the best conditions for the cloud seeding operations. Finally, it is suggested that cloud seeding technology can be used successfully for water harvesting in arid and semi-arid zones.

\section{Acknowledgments}

Authors do appreciate to National cloud seeding Research Center, which help and support to provide this paper materials. I want 
thank to my co worker: Farid Golkar², Vahide Khatibi ${ }^{3}$, Mansure Seyedhassani ${ }^{4}$.

\section{Conflicts of interest}

The author declares there is no conflcit of interest.

\section{References}

1. American Meteorological Society. Planned and inadvertent weather modification. Bull Amer Meteor Soc. 1992;73:331-337.

2. Bureau of Reclamation. Project Skywater, A program of Research in Precipitation Management. However, some research indicates that silver toxicity is bio-accumulative in aquatic environments, causing respiratory distress to some species of fish (Aquatic Toxicology. Final Environmental Statement (INT FES 77-39). 1977;49(1-2):111-129.

3. Christner BC, Morris CE, Foreman CM, et al. Ubiquity of biological ice nucleators in snowfall. SCIENCE. 2008;319(5867):1214.

4. Samaneh Poormohammadi, Mohammad Mehdi Javadian Zadeh Investigating the Effect of Cloud Seeding Technique on Precipitation in Iran Basins in Water Year 2010-2011: A Case Study of Bakhtgan-Task Basin and Gavkhoni Basin. International Bulletin of Water Resources \& Development. 2014;2(3):6
5. Jump up Harris, Edward R. Sierra Cooperative Pilot Project Environmental Assessment and Finding of No Significant Impact. U.S Department of the Interior, Bureau of Reclamation, Denver, CO, 1981. p. 208.

6. Jump up, Hill SA, Ming Yi. Nonlinear climate response to regional brightening of tropical marine stratocumulus. Geophysical Research Letters. 2012;39:L15707.

7. Poormohammadi SM, Javadianzadeh M, Seyedhasani F. Evaluation of cloud seeding effects on basin precipitation (A case study from Iran). Third International Conference on Environmental Management, Engineering, Planning and Economics (CEMEPE 2011), Greece, 2011.

8. Samaneh Poormohammadi, Mohammad Mehdi Javadian Zadeh, Farid Golkar. An Investigation of Increasing Water Resources by Using Cloud Seeding and an Estimation of Its Economical Assessment: A Case Study of Kuhdasht and Rumishgan Catchment. International Bulletin of Water Resources \& Development. 2014;2(3):6.

9. World Meteorological Organization. Weather Modification Program, Precipitation Enhancement Project, Report No. 3. 1976. 